\title{
PRINCIPAIS ABORDAGENS TEÓRICO-METODOLÓGICAS SOBRE A TEORIA DO COMPORTAMENTO: DO POSITIVISMO AO PÓS-MODERNISMO
}

\author{
J. P. CIRIBELI* e W. A. MENDES \\ Faculdade Governador Ozanam Coelho - FAGOC \\ jpciri@hotmail.com* \\ Artigo submetido em março/2014 e aceito em dezembro/2015 \\ DOI: $10.15628 /$ holos.2015.2038
}

\section{RESUMO}

O artigo buscou identificar as principais correntes teórico-metodológicas que contribuíram para o avanço e o entendimento do comportamento do consumidor, bem como aferir suas nuanças, distinções e semelhanças. Quanto à metodologia, o estudo consiste num ensaio teórico, o que nos remete à revisão bibliográfica, onde pode-se confrontar as idéias dos principais autores que discorrem na área, assim como analisar, de forma didática suas arguições. Sobre os resultados, verificou-se que três modelos contribuíram de forma mais substancial ao entendimento do comportamento do consumidor: modernismo, estruturalismo e pós-modernismo. Pode-se constatar também que estes modelos podem ser agrupadas em duas abordagens, a quantitativa e a qualitativa, o que ocasionou, a posteriori, a híbrida. O modernismo, em sua abordagem quantitativa, buscava compreender o comportamento do consumidor de forma objetiva, enquanto o estruturalismo buscava conhecer as estruturas dos fatos e objetos observados. Já o pósmodernismo apresenta uma abordagem qualitativa, onde as experiências, as crenças, os valores e a carga simbólica do comportamento do indivíduo passam a preponderar sobre a análise das massas.

PALAVRAS-CHAVE: Modernismo, Pós-modernismo, Estruturalismo, Comportamento do consumidor, Positivismo.

\section{MAIN APPROACHES THEORETICAL-METHODOLOGICAL ON THE THEORY OF BEHAVIOR: OF THE POSITIVISM TO POSTMODERNISM}

\begin{abstract}
The paper aims to identify the main theoretical and methodological trends that contributed to the advancement and understanding of consumer behavior and measure its nuances, distinctions and similarities. Regarding the methodology, the study consists of a theoretical essay, which brings us to the literature review, where you can confront the ideas of the main authors who talk in the area, as well as analyze, didactically their pleas. On the results, it was found that three models contributed more substantially to the understanding of consumer behavior form: modernism,
\end{abstract}

structuralism and postmodernism. One can also see that these models can be grouped into two approaches, quantitative and qualitative, which caused a posteriori hybrid. Modernism, in its quantitative approach, sought to understand consumer behavior objectively, while structuralism sought to know the structures of the facts and observed objects. Have postmodernism presents a qualitative approach, where the experiences, beliefs, values and symbolic significance of individual behavior shall prevail on the analysis of the masses.

KEYWORDS: Modernism , Postmodernism , Structuralism , Consumer Behavior , Positivism 


\section{INTRODUÇÃO}

A temática 'comportamento do consumidor' se tornou um campo de estudos com vigor acadêmico apenas em fins da década de 1950, embora o consumo já estivesse presente na sociedade há mais tempo. As pesquisas buscavam conhecer melhor os hábitos dos consumidores - seus desejos, necessidades, gostos e preferências, não apenas na etapa da compra, mas ao longo do processo decisório. (BLACKWELL;MINIARD; ENGEL, 2003; KARDES; CRONLEY; CLINE, 2010; BELCH; BELCH, 2011; KOTLER; KELLER, 2012).

Atualmente, fatores como internacionalização empresarial, competitividade, reconhecimento da importância das pesquisas de mercado como um componente estratégico e aumento (em variedade, quantidade e valor agregado) de produtos e serviços, assim como da complexidade das relações sociais favoreceram o aparecimento de novas técnicas e procedimentos metodológicos relacionados às pesquisas do comportamento humano, mas tais estudos tiveram sua influencia, em maior ou menor grau, nas correntes teórico-metodológicas datadas do século XIX e XX.

Em realidade, os estudos do comportamento do consumidor se apropriaram (em parte) dos conceitos e das metodologias positivistas e pós-modernias do século XIX e XX, respectivamente. Tais correntes possuem um arquétipo filosófico e epistemológico que suscitaram uma vasta gama de aplicabilidades, que vão das ciências exatas às ciências biológicas.

Para o presente artigo, buscar-se-á analisar os contributos de tais correntes para o entendimento do comportamento do consumidor, suas nuanças, distinções e semelhanças. Os modelos positivista, estruturalista e pós-modernistas possuem vasta discussão acadêmica, mas ao se analisar suas proposições para a área mercadológica, em especial para análise do comportamento do consumidor, pouco se tem discutido, o que vem a reforçar a necessidade de tal estudo.

Entender o comportamento do consumidor não é tarefa fácil, o que exige a absorção do conhecimento de diversas outras áreas, como a sociologia, antropologia, psicologia, estatística, economia, matemática, física e biologia. Enquanto tais áreas de estudo permitiram o entendimento do comportamento humano, as correntes teórico-metodológicas em análise (positivista, estruturalista e pós-modernistas) buscam nortear o pesquisador sobre a abordagem a ser dada no tratamento das informações, ou seja, sob que perspectiva o objeto deve ser pesquisado, assim como a forma de coleta, tratamento e análise dos dados.

Por ter base nas teorias modernistas, estruturalistas e pós-modernistas, o estudo do comportamento do consumidor é comumente analisado em diferentes áreas, onde empregam-se métodos quantitativos, qualitativos ou mesmo quali-quantitativos, neste caso relacionada a pesquisadores que buscam empregar ambos as metodologias para identificar, com amplitude e profundidade o comportamento do consumidor, a fim de alcançar os resultados necessários e consequentemente tomar a decisão com menor probabilidade de erro.

Em termos metodológicos o presente estudo consiste em um ensaio teórico que visa, para além da revisão bibliográfica (ou pesquisa em fontes secundárias) contribuir para análise crítica do tema e apresentar, de forma didática, as teorias precursoras do estudo do comportamento do consumidor. De acordo com Vergara (2006, p. 48) este tipo de pesquisa consiste no "estudo sistematizado desenvolvido com base em material publicado em livros, revistas, jornais, redes eletrônicas, isto é, material acessível ao público em geral". 


\section{O COMPORTAMENTO DO CONSUMIDOR SOB A ÓTICA MODERNISTA: O SER RACIONAL}

Impulsionada pela corrente Modernista, que vigorou entre o século XIX e a primeira metade do século $X X$, as pesquisas sobre o comportamento do consumidor se tornaram fortes aliadas para os processos organizacionais, onde o conhecimento de suas características auxilia a definição do mercado quanto ao produto ou técnicas empregadas a um público alvo. (SOLOMOM, 2008)

Também conhecida como positivismo, empirismo lógico, operacionalismo e objetivismo, o modernismo assume que somente informações comprovadas cientificamente podem ser utilizadas para tomada de decisão. (BLACKWELL, MINIARD, ENGEL, 2003; SOLOMON, 2008; SHIFFMAN, KANUK, 2012). Em complemento, Solomon (2008, p.55) diz que "O positivismo nos faz reforçar a função dos objetos, celebrar a tecnologia e ver o mundo como um lugar racional e ordenado, com passado, presente e futuro claramente definidos.".

O período modernista pode ser dividido em alguns momentos de evolução, sendo os que se destacam no estudo do comportamento do consumidor, o Positivismo Clássico (cujos autores, sobressaem Auguste Comte, Littré, Spencer e Mill) e o Neopositivismo, que compreende diversas teorias, dentre elas o behaviorismo e o neobehaviorismo. (TRIVIÑOS, 1987).

Pela Figura 1 pode-se identificar como as principais correntes precursoras do estudo do comportamento do consumidor se estruturam, além da abordagem utilizada em suas pesquisas. Vale ressaltar que tais teorias apresentam outras ramificações, com baixa ou nenhuma influencia nos estudos comportamentais, estas ramificações não serão tratadas ao longo do artigo, visto que não irão contribuir (ao menos de forma significativa) para o alcance dos objetivos propostos na introdução.

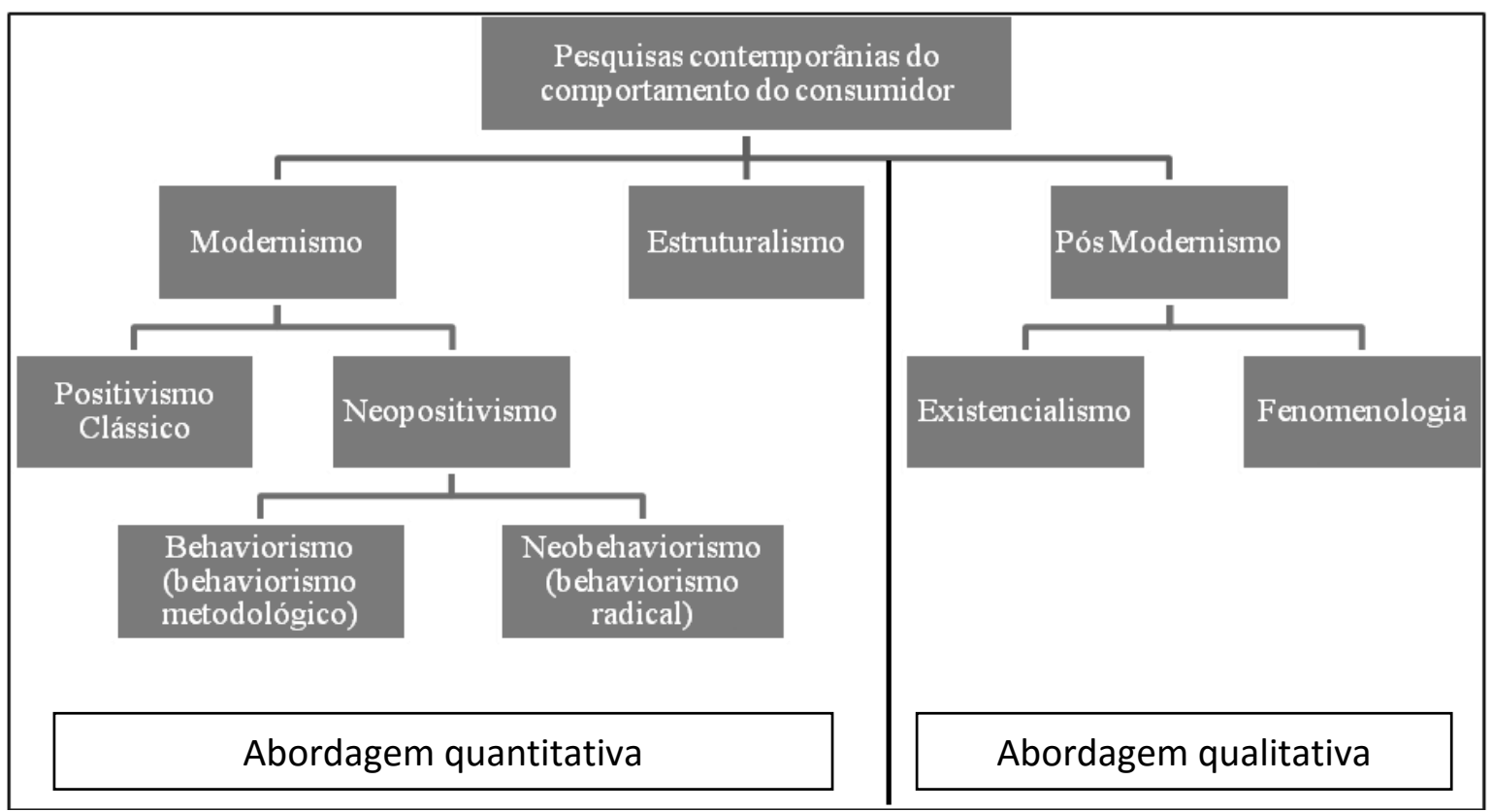

Figura 1: Estrutura das principais correntes teóricas norteadoras do estudo do comportamento do consumidor Fonte: Elaborada pelos autores com base em Triviños (1987), Baum (2005), Carrara (2005) e Moreira e Medeiros (2007). 


\subsection{O Positivismo Clássico}

Segundo Comte (1868) os positivistas observaram a capacidade racional humana, cuja progressão é diretamente proporcional à idade do homem. Para Carrara (2005, p.140), o positivismo, como filosofia, não se diferenciava dos métodos da ciência, "Sua meta principal era a de que princípios gerais comuns a todas as ciências pudessem ser úteis para guiar o comportamento humano para uma melhor organização social.". Esta corrente buscava ainda compreender e predizer o comportamento do consumidor e descobrir a relação de causa e efeito que regulam a persuasão e/ou educação. (BLACKWELL, MINIARD, ENGEL, 2003).

Dessa forma, "Se o objeto de investigação é o comportamento de consumo, a explicação só pode recair sobre fenômenos observáveis.". (GIGLIO, 2005, p. 9). Para melhor análise, o autor dividiu tal estudo, sob a ótica positivista, em dois modos de raciocínio: o indutivo e o dedutivo. No primeiro, há uma abordagem que consiste em criar tipos predominantes de consumidores, sendo a generalização - onde utiliza características comuns à indivíduos para predizer seu comportamento - e a previsão - em que o comportamento é previsto com base no grupo de pessoas em que se convive. Já no método dedutivo, a partir de uma lei geral é previsto fenômenos isolados.

Por utilizar métodos quantitativos, o positivismo assume uma postura objetiva, prática, e de resultados comprováveis, onde suas características metodológicas buscam predizer o comportamento dos consumidores de forma generalizada, torna-se, assim, adequada para elaborar a estratégia organizacional em um determinado contexto.

\subsection{Neopositivismo}

O neopositivismo iniciou com o Círculo de Viena, uma escola de pensadores que se uniam para discutir sobre o conhecimento científico, na matemática, biologia, física, química, filosofia e outras áreas. O Círculo de Viena nasceu na década de 1920, fundado por Mortz Schlick, filósofo alemão, Philipp Franck, Otto Neurath, Rudolf Carnap, Hans Reichenbach. O Círculo também foi impulsionado pelos pensamentos de Ludwig Wittgenstein, que escreveu o estudo de caso Tractatus Logico-philosophicus. (OUTHWAITE; BOTTOMORE; et al 1996; ZILLES, 2006; CHARDIN, 2011).

Durante esse período, o positivismo adotou uma postura baseada no empirismo, teoria que ganhou força com David Hume, Bacon e Hobes, cujo conhecimento deve ser experimental, racional, sensível e científico, obtido com base em fenômenos naturais com observação pública de eventos mensuráveis. (TRIVIÑOS, 1987; VAZ, 2002; GOODWIN, 2005; WAAL, 2007; BAPTISTA, 2012).

A visão do neopositivismo desconsidera a subjetividade humana como objeto de análise, seus pensamentos e sentimentos. Skinner (1994) critica e compara a estrita e estremada visão neopositivista, um homem e um objeto. Tal comparação tem por finalidade demonstrar, para o estudo, a ausência de sentimentos e fatores que influenciam o comportamento.

\subsubsection{Do Behaviorismo ao Neobehaviorismo}

Derivada da palavra behavior, no inglês americano ou, behaviour, no inglês britânico que significa comportamento, o behaviorismo é a filosofia da ciência do comportamento humano. Iniciou com estudos de John B. Watson em 1913, cujo título "Psychology as the Behaviorist Views it" (Psicologia como o behaviorista a vê) conhecido como 'manifesto behaviorista' e teve como 
expoente, Skinner. (SKINNER, 1994; POURTOIS; DESMET, 1999; PALMER, 2002; GERRIG; ZIMBARDO, 2005; GOODWIN, 2005).

Ao contrário da psicologia introspectiva, que era pouco confiável, muito vulnerável a distorções pessoais e subjetivas, o behaviorismo estuda o comportamento humano e suas atividades. É um ramo experimental, cujo objetivo teórico é a previsão e controle do comportamento. (WATSON, 1945; BAUM, 2005).

O behaviorismo pode ser dividido em duas áreas: o behaviorismo metodológico, como principal precursor John B. Watson, e o behaviorismo radical, cujo autor, Burrhus Frederic Skinner. (BAUM, 2005; CARRARA, 2005; MOREIRA; MEDEIROS, 2007). O Quadro 1 esquematiza as relações e as diferenças entre as formas do behaviorismo.

Quadro 1- Behaviorismo metodológico e behaviorismo radical: semelhanças e diferenças.

\begin{tabular}{|c|c|c|}
\cline { 2 - 3 } \multicolumn{1}{c|}{} & Behaviorismo metodológico & Behaviorismo Radical \\
\hline Precursores & John B. Watson & Burrhus Frederic Skinner \\
\hline Base & Realismo & Pragmatismo \\
\hline Objetivos & $\begin{array}{c}\text { Descrever o comportamento em termos } \\
\text { fisiológicos, observáveis. Não analisava o } \\
\text { contexto dos fatos. }\end{array}$ & $\begin{array}{c}\text { Descrever o comportamento em seu } \\
\text { contexto, fatores inobserváveis. }\end{array}$ \\
\hline Semelhanças & É um campo de observação analisado através de métodos científicos, previamente \\
comprovados.
\end{tabular}

Fonte: Elaborado pelos autores, com base em Baum (2005), Carrara (2005) e Moreira e Medeiros (2007).

Primeira versão, conhecida como behaviorismo metodológico, possuía como ideia central a possibilidade de criar uma ciência natural do comportamento, e a psicologia poderia ser ela. Influenciado por preceitos do neopositivismo, a psicologia deveria ser mais objetiva, investigar apenas o comportamento publicamente observável, uma vez que não possuía conteúdo teórico para estudar o comportamento inobservável. (WATSON, 1945; BAUM, 2005; CARRARA, 2005; COON, 2005; MOREIRA; MEDEIROS 2007; FARIAS, 2010).

Expressões como 'mente', 'consciência', 'estados mentais' e 'conteúdo introspectivamente verificável' deveriam ser evitadas para o behaviorismo, para assim, poder estudar de forma livre o comportamento humano e animal. (WATSON, 1945; BAUM, 2005).

O behaviorismo radical, também conhecido como neobehaviorismo, surgiu com foco estudar como se processava a aprendizagem, cujos principais pensadores foram Edward Tolman, Clark Hull e B. F. Skinner. (GOODWIN, 2005).

Ao contrário do behaviorismo de Watson, Skinner considerava que os estados mentais faziam parte do comportamento humano, unindo o comportamento observável com o inobservável. Considera a introspecção e questiona a natureza do sentimento, auto-observação e autoconhecimento. (SKINNER, 1994; MOREIRA; MEDEIROS 2007).

Skinner utiliza um novo termo, o 'mentalismo', que seria uma justificativa incapaz de explicar o fato. Como exemplo a resposta "por que sim" não tem capacidade de justificar qual a verdadeira intenção frente a um ato. Esse seria uma possível limitação para o behaviorismo metodológico não estudar o comportamento inobservável, enquanto o behaviorismo radical buscava o equilíbrio entre os fenômenos externos e internos no ser humano para descrever seu comportamento. (SKINNER, 1994; BAUM, 2005). 


\section{A ABORDAGEM ESTRUTURALISTA E SUAS IMPLICAÇÕES NO ENTENDIMENTO DO MERCADO}

Sobre a linha de pesquisas com métodos quantitativos, o estruturalismo surge como uma alternativa ao modernismo (RICHARDSON, 1999 apud SOUZA NETO; MELLO, 2009). Surgiu aproximadamente na década de 1940, baseada nas ideias de Claude Lévi-Strauss, sob os métodos da Lógica Sistêmica, que aponta o fenômeno humano como o conjunto de características condicionadas. Essa teoria é utilizada para a classificação científica de seres vivos. (GOMES, 2011).

O estruturalismo não busca a origem e o modo como os elementos operam, mas investigar, identificar e explicar as relações entre os objetos. Levi-Strauss considerou os objetos de análises uma matriz algébrica, com a possibilidade de se permutar e combinar. (VIEIRA; ZOUAIN, 2006). Para Mattar (2012, p.75) "O estruturalismo defende que a realidade como a entendemos também é composta de estruturas." Desta forma, conseguimos verificá-las na arquitetura, no corpo, nas línguas, na psicologia, na matemática, na geologia, na anatomia, nas ciências humanas e sociais.

O estruturalismo busca a redução dos fatos até sua essência, eliminando assim, tudo o que é superficial e variável, dessa forma, utilizam conceitos da inconsciência para explicar os fatos. (GIGLIO, 2005).

As relações entre os objetos ganham notoriedade estudadas nas ciências sociais, mais precisamente na mercadologia, quando se leva em consideração os avanços contemporâneos, como os gostos homogênicos, incitados por pressão das mídias, também conhecido como o modismo. As pesquisas estruturalistas podem ainda ser utilizadas a fim de identificar padrões cognitivos do consumidor. (SOUZA NETO; MELLO, 2009).

Porém, mesmo com tais possibilidades de estudo, o estruturalismo não teve muitos adeptos, por possuir métodos cuja aplicabilidade era bem compreendida. Alguns pesquisadores criaram o pós-estruturalismo, com objetivo de completar as lacunas do estruturalismo, mas mesmo com esses esforços, para alguns estudiosos, o pós-estruturalismo possuía as mesmas ideias e falhas do estruturalismo.

\section{O PÓS-MODERNISMO E SUAS TEORIAS DO COMPORTAMENTO SUBJETIVO}

Diferente das teorias quantitativas, as teorias qualitativas do comportamento do consumidor leva em consideração fatores que influenciam o processo de consumo. Suas pesquisas buscam descrever o fato como um todo, desviando da objetividade proposta pelo modernismo.

As principais correntes surgiram após a Segunda Guerra Mundial, pelo fato das ideias modernistas já não contentavam alguns pesquisadores, através de sua ausência de subjetividade, forma rígida e calculista, o desconhecimento de fatores externos ao indivíduo, impulsionou as pesquisas para conhecer o comportamento individual de forma subjetiva, mais completa (na visão de seus precursores), através de ferramentas qualitativas.

O pós-modernismo, também chamado de interpretativismo, experiencialismo, naturalismo, humanismo ou pós-positivismo, se tornou popular nos anos de 1980 e utilizava como ferramentas de compreensão do comportamento do consumidor, métodos qualitativos, através de entrevistas, grupos de enfoques e análises metafóricas. (BLACKWELL, MINIARD, ENGEL, 2003; SHIFFMAN, KANUK, 2012). Dentre os precursores destacam-se: Michel Foucault, Jacques Derrida, Jean-Froçois Lyotard, Richard Rorty. (HICKS, 2011).

O pós-modernismo estava mais interessado no processo de decisão de compra do que unicamente no ato de comprar, ou seja, buscava uma perspectiva social mais ampla. Neste caso 
entende-se o comportamento do consumidor como um subconjunto do comportamento humano, caracterizado como pessoal e único, desta forma, o pós-modernismo busca estudar grupos específicos de consumidores, onde suas técnicas conseguem descrever em detalhes o comportamento de determinado indivíduo. (KARDES, CRONLEY, CLINE, 2010; SHIFFMAN, KANUK, 2012).

O pós-modernismo não nega a eficácia do método quantitativo para o estudo de objetos, mas enfatiza a necessidade de métodos diferentes para estudar a singularidade humana. A escola interpretativista (por exemplo) argumenta que deve-se estudar qualquer experiência de consumo, individualmente, para assim poder compreender melhor o comportamento. (WILLIAMS, 2002; BERNARD, 2013).

Para Solomon (2008, p. 645), o pós-modernismo enfatiza "a importância da experiência simbólica e subjetiva e a ideia de que o significado está na mente da pessoa e não existe 'fora', no mundo objetivo". Para Kardes, Cronley e Cline (2010) o método qualitativo utilizado busca descrever uma experiência individual e subjetiva do consumo de um produto ou serviço. Os autores entendem que o comportamento humano se difere de pessoa para pessoa, sofrem interferências externas, são complexos e de baixa racionalidade.

\subsection{Pontos focais da fenomenologia e do existencialismo}

A fenomenologia surgiu entre as três primeiras décadas do século XX e, assim como o pósmodernismo, buscava descrever o comportamento com base em fatos observáveis. É a parte da tradição pós-modernista que enfatiza a experiência comum de todos os seres humanos e a habilidade em se relacionar. (BERNARD, 2000, apud VIEIRA; ZOUAIN, 2006).

Golding (1999, apud VIEIRA; ZOUAIN, 2006), questiona o uso da fenomenologia no estudo do comportamento do consumidor, onde chama a atenção para o fato de que a fenomenologia não é somente um conjunto de técnicas de estudo de dados, mas uma filosofia, cujos fundamentos intelectuais necessitam ser entendidos para que sua utilização seja correta.

Como uma crítica ao modernismo, Husserl (1859 - 1938) escreveu o livro 'A filosofia como ciência do rigor', onde surgiu o método fenomenológico e a teoria existencialista. Nessa perspectiva, observa-se uma aproximação dos estudiosos para a fenomenologia existencialista, conhecida também como existencialismo, desenvolvida por Heidegger, que era apresentada como uma alternativa para estudar a experiência de consumo. O método fenomenológico começou como um estudo da consciência humana, com a tentativa de definir o que é essencial para qualquer experiência, e considera como real tudo o que existe, sendo perceptível ou abstrato. (SOLOMON, 2001; GIGLIO, 2005; VIEIRA; ZOUAIN, 2006).

Para Mascarenhas (2012, p. 44) "o método fenomenológico busca descrever o fenômeno do jeito que ele é." Ele continua sua ideia e afirma que a fenomenologia não busca descobrir a verdade, mas interpretá-la. Essa interpretação é subjetiva, onde pode sofrer alterações de indivíduo para indivíduo.

O existencialismo, baseada na filosofia de Edmund Husserl e Martin Heidegger, popularizou-se com os textos de Jean-Paul Sartre, Simon de Beauvoir, Maurice Merleau-Ponty e Albert Camus. (TRIGO, 2011; GIGLIO, 2005). É "uma vertente filosófica pluralista em termos de concepção sobre a eventual transcendentalidade." (TRIGO, 2011, p.18). Em complemento, Giglio (2005, p. 54) diz "é um movimento filosófico científico que critica os princípios rígidos da ciência positiva, afirmando que há uma relação indissociável do ser com o mundo.". 
O existencialismo consiste em observar os fatos para depois criar teorias adequadas, mesmo que necessite repetir o processo até encontrar a sua essência, neste método pode-se afirmar que "que o ser humano é único na sua existência, mesmo que, por recursos metodológicos, possamos representa-lo dentro de tendências de grupo." (GIGLIO, p. 56, 2005). O existencialismo admite ainda que "a pessoa é um corpo vivo, uma consciência psicológica e uma razão lógica, e faz depender o encontro com o que a cerca desses elementos que a integram." (CARVALHO, p. 28, 2008).

Em uma acareação entre o existencialismo e o estruturalismo, pondera-se que os pontos metodológicos iniciais são convergentes - na medida em que consideram o empirismo, ou seja, a observação de fenômenos e fatos reais. No entanto, enquanto o existencialismo se preocupa em conhecer o individuo (sua essência), o estruturalismo visa identificar padrões e estruturas existentes nos diversos relacionamentos entre os indivíduos (consciência) e sua realidade (mercado).

\section{A CONVERGÊNCIA DAS CORRENTES TEÓRICAS PARA UM MODELO HÍBRIDO SOBRE O ESTUDO DO COMPORTAMENTO DO CONSUMIDOR}

O campo de estudo do comportamento do consumidor é inter e trans disciplinar, cujo objetivo é identificar os desejos e as necessidades dos consumidores. Essa variabilidade metodológica possibilita aos pesquisadores tomarem diferentes caminhos, conforme a sua necessidade, seu bom senso e principalmente a natureza da pesquisa. (SOLOMON, 2008; RIVAS; ESTEBAN, 2010).

As atuais pesquisas empregam metodologias derivadas do modernismo e do pósmodernismo, sendo incorreto afirmar qual é o método correto, ou mais correto. Pode-se sim afirmar que, num determinado contexto, levando-se em consideração os objetivos da pesquisa, existe métodos que são mais adequados do que outros.

Diferentes abordagens metodológicas contribuem para o conhecimento acerca do consumidor: seja através de pesquisas quantitativas (derivadas do modernismo), que contribuem para conhecer como grupos de pessoas reagem frente a determinadas campanhas publicitárias, seja por meio das pesquisas qualitativas (derivadas do pós-modernismo), cujo emprego tem finalidade de compreender como a cultura, fatores sociais e econômicos interferem no indivíduo no processo de consumo. (BELCH; BELCH, 2011; SHIFFMAN; KANUK, 2012).

As pesquisas quantitativas são utilizadas para prever o comportamento, descrever as características do mercado alvo, e assim auxiliar a tomada de decisões estratégicas, além de identificar as relações de causa e efeito no processo de compra. Por outro lado, as qualitativas são destinadas a identificar reações frente a novas ideias de produto e estratégias de posicionamento, onde busca conhecer as reais motivações para consumir determinado produto. (SHIFFMAN; KANUK, 2012).

O Quadro 2 aponta algumas características das principais correntes do pensamento que deram base às pesquisas do comportamento do consumidor. Essa análise é importante para identificar como essas teorias eram empregadas e como deram origem à metodologia da pesquisa híbrida, além de suas respectivas contribuições para o estudo do comportamento do consumidor.

Quadro 2 - Comparativo das principais correntes de pensamento e das atuais pesquisas do comportamento do consumidor 


\begin{tabular}{|c|c|c|c|c|}
\hline Correntes & Modernismo & Estruturalismo & Pós-modernismo & Versão híbrida \\
\hline Início & $\begin{array}{l}\text { Primeira metade } \\
\text { do século XIX }\end{array}$ & 1940 & $\begin{array}{c}\text { Pós 2a Guerra Mundial. } \\
\text { Tornou-se popular em } \\
1980\end{array}$ & $\begin{array}{l}\text { Segunda metade do } \\
\text { século } X X\end{array}$ \\
\hline Objetivo & $\begin{array}{l}\text { - A comprovação } \\
\text { de métodos } \\
\text { científicos; } \\
\text { - Processos } \\
\text { racionais; } \\
\text { - Objetividade. }\end{array}$ & $\begin{array}{l}\text { - Compreender as } \\
\text { estruturas que } \\
\text { formam os objetos } \\
\text { de análise; } \\
\text { - Mudança da razão } \\
\text { pela formalização. }\end{array}$ & $\begin{array}{l}\text { - Estudar o objeto } \\
\text { individualmente; } \\
\text { - É subjetivo. }\end{array}$ & $\begin{array}{c}\text { Compreender como } \\
\text { o consumidor se } \\
\text { comporta, pensa e } \\
\text { age. }\end{array}$ \\
\hline Abordagem & Quantitativo & Quantitativo & Qualitativo & Quanti e qualitativo \\
\hline Principais autores & $\begin{array}{l}\text { Auguste Comte, } \\
\text { Litré, Spencer, } \\
\text { Mill, Avenarius, } \\
\text { Mach, Mortz } \\
\text { Schilick, Philipp } \\
\text { Franck, Otto } \\
\text { Neurath, Rudolf } \\
\text { Carnap, Hans } \\
\text { Reichenbach }\end{array}$ & Claude Lévi-Strauss & $\begin{array}{l}\text { Michel Foucault, } \\
\text { Jacques Derrida, Jean- } \\
\text { Froçois Lyotard, } \\
\text { Richard Rorty, Jean- } \\
\text { Paul Sartre, Edmund } \\
\text { Husserl, Martin } \\
\text { Heidegger, Simon de } \\
\text { Beauvois, Maurice } \\
\text { Meleau-ponty e } \\
\text { Aulbert Camus. }\end{array}$ & $\begin{array}{l}\text { Marcel Mauss, } \\
\text { Thrstein Veblen, } \\
\text { Mary Douglas, } \\
\text { Marshall Sahlins, } \\
\text { Jean Baudrillard, } \\
\text { Colin Campbell, } \\
\text { Daniel Miller. }\end{array}$ \\
\hline $\begin{array}{l}\text { Contribuição para } \\
\text { as pesquisas do } \\
\text { comportamento } \\
\text { do consumidor }\end{array}$ & $\begin{array}{c}\text { Compreende o } \\
\text { comportamento } \\
\text { de grande volume } \\
\text { de pessoas }\end{array}$ & $\begin{array}{l}\text { Identifica padrões } \\
\text { de } \\
\text { comportamentos. }\end{array}$ & $\begin{array}{c}\text { Compreende o } \\
\text { comportamento } \\
\text { individual }\end{array}$ & $\begin{array}{c}\text { Identifica o } \\
\text { comportamento em } \\
\text { sua amplitude e } \\
\text { profundidade. }\end{array}$ \\
\hline Limitações & $\begin{array}{l}\text { Não consegue } \\
\text { compreender a } \\
\text { singularidade do } \\
\text { comportamento }\end{array}$ & $\begin{array}{l}\text { Método com } \\
\text { fundamento pouco } \\
\text { conhecido, com } \\
\text { aplicabilidade não } \\
\text { adequadamente } \\
\text { compreendida. }\end{array}$ & $\begin{array}{c}\text { Não é possível } \\
\text { generalizar os } \\
\text { resultados de suas } \\
\text { pesquisas, devido à } \\
\text { abordagem individual } \\
\text { que utiliza. }\end{array}$ & $\begin{array}{c}\text { Combinar a } \\
\text { abordagem } \\
\text { qualitativa com a } \\
\text { quantitativa. }\end{array}$ \\
\hline
\end{tabular}

Fonte: elaborado pelos autores, com base em Miniard e Engel (2003), Giglio (2005), Vieira e Zouain (2006), Blackwell, Kardes, Cronley e Cline (2010), Belch e Belch (2011), Mattar (2012), Shiffman e Kanuk (2012).

A reflexão sobre um possível método híbrido, comumente conhecido como quali-quanti, quali-quantitativo, quanti-quali ou quanti-qualitativo, tem por objetivo identificar os fatores que interferem o comportamento do consumo numa dupla abordagem. Os estudiosos esperavam que os questionamentos que um método não fosse capaz de responder, pudessem ser respondidos quando observados em conjunto com o outro modelo.

A intenção é, portanto, acrescentar no objetivismo empregado pelo modernismo, a análise subjetiva proposta pelo pós-modernismo, e vice-versa. Pretende-se assim com tal complementação metodológica obter dados mais fiéis sobre o comportamento do consumidor.

Porém, as formas de pesquisa quantitativa e qualitativa possuem caráter distinto para obtenção de dados. Seus objetivos, formas de abordagens e ferramentas de captura de dados, por muitas vezes, impedem que sejam utilizadas em conjunto em uma mesma pesquisa.

Para a empregabilidade do método híbrido, os modelos quantitativos e qualitativos devem ser utilizados em pesquisas diferentes, onde somente seus resultados serão analisados em conjunto para melhor compreensão do estudo (SHIFFMAN; KANUK, 2012). Ambas as formas de pesquisa, quantitativo e qualitativo, portanto, são importantes para compreensão do comportamento do consumidor, enquanto a primeira identifica o comportamento em sua amplitude, a segunda busca identificar os fatores que o influencia. 


\section{CONSIDERAÇÕES FINAIS}

$\mathrm{O}$ artigo buscou compreender melhor as principais correntes teórico-metodológicas que contribuíram para o avanço e o entendimento do comportamento do consumidor, assim como verificar os pontos de convergência e cisão de tais modelos.

Com base na revisão bibliográfica pode-se perceber que existem basicamente três modelos que contribuíram, e ainda contribuem, para o entendimento do consumidor, quais sejam: modernismo, estruturalismo e pós-modernismo. Verificou-se ainda que tais orientações podem ser agrupadas em duas abordagens, a quantitativa e a qualitativa, o que ocasionou, a posteriori, a abordagem híbrida.

O modernismo, em sua abordagem quantitativa, buscava compreender o comportamento do consumidor de forma objetiva, ou seja, analisava os fatos de forma objetiva e desconsiderava o contexto do objeto em estudo. Tal abordagem é empregada para identificar o consumidor e seu comportamento de forma ampla, com possibilidade de generalização dos resultados via técnicas estatísticas de amostragem, coleta e tratamento dos dados.

Apesar de sua orientação quantitativa o estruturalismo, diferentemente do modernismo, buscava conhecer as estruturas dos fatos e objetos observados - tentava extrair a essência da realidade. Com vistas a identificar a estrutura, os padrões e os vícios de comportamento esta abordagem contribui na medida em que não se atenta ao que, como e quando se consome, mas às relações entre os objetos - considerava por tanto o ambiente no qual o consumidor está inserido. Embora o estruturalismo buscasse a simplificação dos fatos por meio da eliminação do que é superficial, pouca aplicabilidade teve este modelo, devido a dificuldade em se chegar à essência dos fatos.

O terceiro modelo, denominado de pós-modernismo, surgiu durante a segunda metade do século $X X$, e apresenta uma abordagem substancialmente diferente das duas primeiras. Neste momento as experiências, as crenças, os valores e a carga simbólica do comportamento do indivíduo passam a preponderar sobre a análise das massas, tem-se então uma abordagem qualitativa.

Como visto ao longo do estudo, os três modelos apresentam abordagens, limitações e propostas distintas, o que permite ao pesquisador escolher o modelo que melhor se adéque ao seu objetivo de estudo. No entanto, recentemente, percebe-se entre alguns pesquisadores a tentativa de utilizar um modelo híbrido para análise do comportamento do consumidor, mas isto não é tarefa fácil, afinal utilizar abordagens tão distintas para uma mesma pesquisa torna o processo de coleta de dados um desafio, por vezes impraticável.

\section{REFERÊNCIAS}

1. BAPTISTA, William José. $\mathbf{O}$ devir da verdade: fundações da filosofia. 1. ed. Rio de Janeiro: Letra Capital, 2012.

2. BAUM, William M. Compreender o behaviorismo: Comportamento, cultura e evolução. 2. ed. Porto Alegre: Artmed, 2005.

3. BELCH, Georg E.; BELCH, Michael A. Propaganda e promoção: uma perspectiva da comunicação integrada de marketing. 7. ed. Porto Alegre: AMGH, 2011.

4. BERNARD, Harvey Russell. Social research method: qualitative and quantitative approaches. 2.ed. Los Angeles: Sage, 2013. 
5. BLACKWELL, Roger D.; MINIARD, Paul W.; ENGEL, James F. Comportamiento del consumidor. 9. ed. Santa Maria la Ribera: Thomson, 2003.

6. CARRARA, Kester. . Behaviorismo Radical: Crítica e Metacrítica. 2. ed. São Paulo: Editora UNESP, 2005.

7. CARVALHO, José Maurício de. Estudos de filosofia clínica: uma abordagem fenomenológica. 1. ed. Curitiba: Editora IBPEX, 2008.

8. CHARDIN, Teilhard de. O fenômeno humano. 15. ed. São Paulo: Cultrix, 2011.

9. COMTE, Auguste. The Positive Philosophy. 1. ed. New York: William Gowans, 1868.

10. COON, Dennis. Psicología. 10. ed. Buenos Aires: Thomson, 2005.

11. FARIAS, Ana Karina C. R. de. Análise comportamental clínica: aspectos teóricos e estudos de caso. 1. ed. Porto Alegre: Artmed, 2010.

12. GERRIG, Richard J.; ZIMBARDO, Philip G. A psicologia e a vida. 16. ed. Porto Alegre: Artmed, 2005.

13. GIGLIO, Ernesto Michelangelo. Comportamento do consumidor. 3. ed. São Paulo: Pioneira Thomson Learning, 2005.

14. GOMES, Mércio Pereira. Antropologia hiperdialética. 1. ed. São Paulo: Contexto, 2011.

15. GOODWIN, C. James. História da psicologia moderna. 1. ed. São Paulo: Cultrix, 2005.

16. HICKS, Stephen R. C. Explicando o Pós-modernismo: ceticismo e socialismo, de Rosseau a Foucault. 1. ed. São Paulo: Callis Ed., 2011.

17. KARDES, Frank R., CRONLEY, Maria L., CLINE, Thomas W. Consumer Behavior. 1. ed. Mason: Cengage Learning, 2010.

18. KOTLER, Philip; KELLER, Kelvin Lane. Administração de marketing. 14. ed. São Paulo: Pearson Education do Brasil, 2012.

19. MASCARENHAS, Sidnei Augusto. Metodologia científica. 1. ed. São Paulo: Pearson Education do Brasil, 2012.

20. MATTAR, João. Filosofia. 1. ed. São Paulo: Pearson Education do Brasil, 2012.

21. MOREIRA, Márcio Borges; MEDEIROS, Carlos Augusto. Princípios básicos de análise do comportamento. 1.ed. Porto Alegre: Artmed, 2007.

22. OUTHWAITE, William; BOTTOMORE, Tom; et. al. Dicionário do pensamento social do Século XX. 1.ed. Rio de Janeiro: Zahar, 1996.

23. PALMER, Michael. Problemas morais em medicina: curso prático. 1. ed. São Paulo: Edições Loyola, 2002.

24. POURTOIS, Jean-Pierre; DESMET, Huguette. A educação pós-moderna. 1. ed. São Paulo: Edições Loyola, 1999.

25. RIVAS, Javier Alonso; ESTEBAN, Ildefonso Grande. Comportamiento del consumidor: decisiones y estratégia de marketing. 6. ed. Madrid: Esic Editorial, 2010.

26. SHIFFMAN, Leon G.; KANUK, Leslie Lazar. Comportamento do consumidor. 9. ed. Rio de Janeiro: LTC, 2012. 
27. SKINNER, B. F. Sobre el conductismo. 1. ed. Buenos Aires: Editorial Planeta Argentina, 1994.

28. SOLOMON, Michael R. O comportamento do consumidor: Comprando, possuindo e sendo. 1. ed. São Paulo: Bookman, 2008.

29. SOLOMON, Robert C. Phenomenology and Existentialism. 3. ed. Oxford:Rowman \& Littlefield Publishers, 2001.

30. SOUZA NETO, Arcanjo Ferreira de; MELLO, Sérgio Carvalho Benício de. Olhando além do "Primeiro Estruturalismo" para a Pesquisa em Marketing. RAC, Curitiba: v. 13, n. 4, p 525-544, Out/Dez. 2009.

31. TRIGO, Luiz Gonzaga Godoi. Existencialismo: um enfoque cultural. 1. ed. Curitiba: Ibpex, 2011.

32. TRIVIÑOS, Augusto Nibaldo Silva. Introdução à pesquisa em ciências sociais: a pesquisa qualitativa em educação. 1. ed. São Paulo: Atlas, 1987.

33. VAZ, Henrique Cláudio de Lima. Ética e Direito. 1.ed. São Paulo: Edições Loyola, 2002.

34. VERGARA, S. C. Projetos e relatórios de pesquisa em administração. 7. ed. São Paulo: Atlas, 2006.

35. VIEIRA, Marcelo Milano Falcão; ZOUAIN, Deborah Moraes. Pesquisa qualitativa em administração. 2. ed. Rio de Janeiro: Editora FGV, 2006.

36. WAAL, Cornelis de. Sobre pragmatismo. 1. ed. São Paulo: Edições Loyola, 2007.

37. WATSON, John B. El conductismo. 1. ed. Buenos Aires: Editorial Paidos, 1945.

38. WILLIAMS, Alastair. Understanding the Hospitality Consumer. 1. ed. Oxford: Butterworth Heinemann, 2002.

39. ZILLES, Urbano. Teoria do conhecimento. 5. ed. Porto Alegre: EDIPUCRS, 2006. 